УДК 661.183.2:544.723

\title{
ПОЛУЧЕНИЕ АКТИВНОГО УГЛЯ ИЗ РАСТИТЕЛЬНЫХ ОСТАТКОВ И ОЦЕНКА ЕГО АДСОРБЦИОННЫХ СВОЙСТВ
}

\author{
(C) Л.Н. Григорьев ${ }^{1 *}$, Л.Г. Веренцова ${ }^{1}$, О.А. Нанова ${ }^{2}$, А.А. Родионова ${ }^{1}$ \\ ${ }^{1}$ Санкт-Петербургская государственная химико-фрармацевтическая \\ академия, ул. профрессора Попова, 14, Санкт-Петербург, 197376 (Россия), \\ e-mail: grig.lev@mail.ru \\ ${ }^{2}$ Санкт-Петербургский государственный технологический университет \\ растительных полимеров, ул. И.Черных, 4, Санкт-Петербург, 198095 \\ (Россия), e-mail: oshanova@gmail.com
}

На основе растительных остатков, образующихся после экстракционной обработки корневища и корня элеутерококка колючего, методом газовой активации получены образцы активного угля, для которого определены объемы пор и содержание кислотных и основных групп. На примере стрептомицина показана возможность использования адсорбционного метода для извлечения антибиотиков из водных растворов и сточных вод. При оценке равновесной адсорбции стрептомицина из модельной сточной воды показано, что полученный активный уголь в области малых значений концентраций незначительно уступает промышленным углям с развитой пространственной структурой (типа СКТ) и может быть рекомендован для практического применения в системах очистки сточных вод. Выяснено, что при концентрациях стрептомицина в воде ниже 100 мг·дм ${ }^{-3}$ нецелесообразно использовать в качестве адсорбента дополнительно окисленный активный уголь. Для расчета равновесной адсорбции стрептомицина на полученном угле предложено использовать уравнение Дубинина - Радушкевича с экспериментально определенными константами; линейные формы уравнений Ленгмюра и Брунауера, Эммета, Теллера (БЭТ) при адсорбции малых концентраций стрептомицина на полученном образце не соблюдаются, что ограничивает возможность использования их в расчетной практике.

Определено, что более высокие значения адсорбционной активности изученного образца угля достигаются при проведении процесса очистки в нейтральной и слабо щелочной средах.

Ключевые слова: шрот, активный уголь, окисленный уголь, адсорбция, стрептомицин, хемосорбция, изотермы, уравнения изотерм, сточные воды

\section{Введение}

Переработка растительного сырья с целью извлечения лекарственной субстанции сопровождается образованием достаточно большого количества отходов - растительных остатков (шрота).

Из известных технологий обращения с такого типа отходами можно отметить получение гранулированных материалов (пеллет), используемых в качестве биотоплива, и активных углей, одним из направлений применения которых являются системы очистки сточных вод и водоподготовки.

Из загрязняющих сточные воды веществ в последние годы значительное внимание уделяется анти-

Григорьев Лев Николаевич - заведующий кафедрой промышленной экологии, доктор технических наук, профессор, e-mail: grig.lev@mail.ru

Верениова Людмила Георгиевна - кандидат химических наук, доцент, e-mail: grig.lev@mail.ru

Шанова Ольга Александровна - заведующая кафедрой

«Охрана окружающей среды и рациональное

использование природных ресурсов», кандидат технических наук, e-mail: oshanova@gmail.com

Родионова Анна Александровна - магистр экологии, ассистент, e-mail: oshanova@gmail.com биотикам [1], которые классифицируются как опасные, высокоопасные, а некоторые и чрезвычайно опасные вещества для окружающей среды.

Надежные данные по адсорбции растворенных антибиотиков из сточных вод на активных углях в доступной литературе встречаются мало. Адсорбция близких (по молекулярной массе) к рассматриваемой теме веществ из физиологических растворов изучалась в работах $[2,3]$. Однако полученные результаты относились только к ре-

\footnotetext{
* Автор, с которым следует вести переписку.
} 
шению задач, связанных с очисткой крови, а сами адсорбенты рассматривались как гемосорбенты. В работе [4] приведены результаты адсорбционного извлечения из водных растворов ряда антибиотиков на энтеросорбенте Силикс; в ряде публикаций по материалам конференций приводятся данные по адсорбции антибиотиков на углеродных нанотрубках [5]. Наиболее детально изучена адсорбция антибиотиков группы нитроимидазолов на активных углях [6]. Следует отметить, что в работах [2-4] опыты проводились при достаточно высоких концентрациях (выше 200 мг·дмㄱ); для более низких концентраций экспериментальные данные встречаются крайне редко и практически не обсуждаются.

Основная задача работы - выявление особенностей адсорбции малых концентраций антибиотика из водных растворов на активном угле, полученном из растительных остатков.

\section{Экспериментальная часть}

В качестве антибиотика использовали стрептомицин.

Активный уголь условной марки АУ-1 получали путем пиролиза растительных остатков (шрота), образующихся после экстракционной обработки корневища и корня элеутерококка колючего. Исходный сырьевой материал просеивался на сите с целью удаления крупных грубых включений, увлажнялся, смешивался с гидролизным лигнином в смесителе и гранулировался на шнековом грануляторе через фильеры диаметром $6,5 \cdot 10^{-3}$ м. Гранулы высушивались до воздушно-сухого состояния при температуре $373-378$ К. Пиролиз и активация осуществлялись в вертикальной кварцевой реторте с объемом загрузки $0,12 \cdot 10^{-3} \mathrm{M}^{3}$, помещенной в трубчатую муфельную печь. Пиролиз проводился практически без доступа воздуха в атмосфере продуктов реакции при температуре 773-823 К в течение 1,5 ч; активирование осуществляли в среде баллонного диоксида углерода при температуре $1100 \mathrm{~K}$ до потери массы угля 55-60\% от его исходного количества.

Объемы пор для образца АУ-1 определяли по методике, разработанной А.В. Киселевым и К.Д. Щербаковой, приведенной в [7]; функциональные группы анализировали титрованием 0,1н растворами NaOH и $\mathrm{HCl}$ в присутствии индикаторов с учетом рекомендаций [8]. Характеристика активного угля приведена в таблице 1.

Для сравнительной оценки адсорбционной активности угля АУ-1 был выбран промышленный уголь СКТ, который относится к группе углей с развитой пространственной структурой; для выбранного угля известен также состав кислородсодержащих групп.

В работе были также изучены образцы угля АУ-1, окисленные пероксидом водорода (водные растворы пероксида водорода с различным содержанием $\mathrm{H}_{2} \mathrm{O}_{2}: 7,5 ; 15,0$ и 30,0 г· $\Gamma^{-1}$ угля) в течение 1 ч.

Водные растворы стрептомицина готовили на основе готовой лекарственной формы (стрептомицина сульфата - $\left(\left(\mathrm{C}_{21} \mathrm{H}_{39} \mathrm{~N}_{7} \mathrm{O}_{12}\right)_{2} \cdot 3 \mathrm{H}_{2} \mathrm{SO}_{4}\right)$ в диапазоне концентраций 5,0-200,0 мг·дм ${ }^{-3}$ (в пересчете на стрептомицин).

Одним из основных адсорбционных показателей, используемых в инженерной практике при определении необходимой массы адсорбента и продолжительности его работы, является величина равновесной адсорбции.

Исходные данные для построения изотерм адсорбции получали ампульным способом в статических условиях по общепринятой методике [11]; для каждой точки на изотерме проводилось два, иногда три параллельных опыта. Аналитическое определение концентрации стрептомицина проводили по методике [12]. В предварительных опытах было определено время установления адсорбционного равновесия, которое составило 26 ч.

Таблица 1. Характеристика активных углей

\begin{tabular}{c|c|c|c|c|c|c|c}
\hline Марка угля & \multicolumn{2}{|c|}{ Удельный объем пор, $\mathrm{cm}^{3} \cdot \Gamma^{-1}$} & \multicolumn{3}{|c}{ Концентрация кислородсодержащих групп, мг-экв· $\Gamma^{-1}$} \\
\cline { 2 - 8 } & $\mathrm{V}_{\text {ми }}$ & $\mathrm{V}_{\text {пा }}$ & $\mathrm{V}_{\text {ма }}$ & фенольные & карбоксильные & альдегидные & основные \\
\hline СКТ [9, 10] & 0,51 & 0,20 & 0,27 & 0,095 & 0,558 & - & 0,653 \\
АУ-1 & 0,35 & 0,11 & 0,35 & 0,096 & 0,135 & 0,106 & 0,154 \\
\hline
\end{tabular}

\section{Обсуждение результатов}

На рисунке 1 представлены изотермы адсорбции стрептомицина при температуре $291 \pm 2$ К. Из рисунка 1 видно, что в изученном диапазоне концентраций (C) стрептомицина активный уголь СКТ является более активным адсорбентом. Однако в области малых значений концентраций стрептомицина (не более 
25 мг·дм ${ }^{-3}$ ) величина адсорбции его на угле АУ-1 мало отличается от таковой на угле СКТ. Заметные различия в величинах адсорбции наблюдаются при концентрациях выше 50 мг·дм ${ }^{-3}$, вследствие, видимо, различия в объемах переходных и микропор, соизмеримых с размерами молекулы адсорбата (при ориентировочном расчете диаметр молекулы стрептомицина близок к 1,0 нм, а площадь, занимаемая молекулой на поверхности, составляет около 0,8 нм$^{2}$ ). При этом не исключается проявление вклада в процесс адсорбции хемосорбционного эффекта, обусловленного присутствием на активных центрах функциональных кислородсодержащих групп (табл. 1): кислотных и основных (в обменных реакциях); альдегидных - в реакциях присоединения.

В определенной степени основанием для проявления хемосорбционного эффекта является то, что с повышением температуры величина адсорбции стрептомицина имеет тенденцию к некоторому увеличению: так, при повышении температуры с 291 до 343 К величина адсорбции стрептомицина на угле АУ-1 повышается с 54,29 до 69,20 мг· $\Gamma^{-1}$ (при концентрации стрептомицина - 50,08 мг·дм ${ }^{-3}$. Вклад специфической адсорбции отмечается и при изучении адсорбции других антибиотиков [6]; однако температурный фактор не является однозначным, так как повышение температуры при адсорбции в микропорах может способствовать их расширению и тем самым большей доступности и усилению вклада неспецифической адсорбции. Выпуклый характер, по отношению к оси концентраций, изотерм свидетельствует больше о преобладающем характере неспецифической адсорбции стрептомицина. Судя по малому содержанию кислородсодержащих групп в угле АУ-1 (табл. 1), проявление хемосорбционного эффекта возможно в области низких концентраций стрептомицина сульфата.

Обычно для усиления вклада хемосорбционной составляющей процесса адсорбции за счет повышения концентрации кислотных (в основном карбоксильных и фенольных) групп применяют окисленные активные угли. На рисунке 2 приведены изотермы адсорбции стрептомицина на угле АУ-1, окисленном пероксидом водорода в различных дозах относительно массы угля.

Как видно из рисунка 2, в области концентраций стрептомицина (до 50 мг·дм ${ }^{-3}$ ) изменение дозы окислителя в изученном интервале практически не влияет на величину адсорбции стрептомицина, которая при этом является более низкой по сравнению с адсорбцией стрептомицина на неокисленном угле. Обращает на себя внимание изменение в этой области концентраций формы изотермы адсорбции на окисленном угле с выпуклой, относительно оси концентраций, на вогнутую, что свидетельствует о повышении полярности адсорбента (вероятнее всего, за счет повышения концентрации кислотных групп) и слабом неспецифическом взаимодействии в системе стрептомицин - матрица активного угля в начальном ее участке [13]; это взаимодействие начинает заметно проявляться только при более высоких значениях концентрации стрептомицина, что выражается в повышении величин адсорбции по сравнению с адсорбцией на неокисленном активном угле.

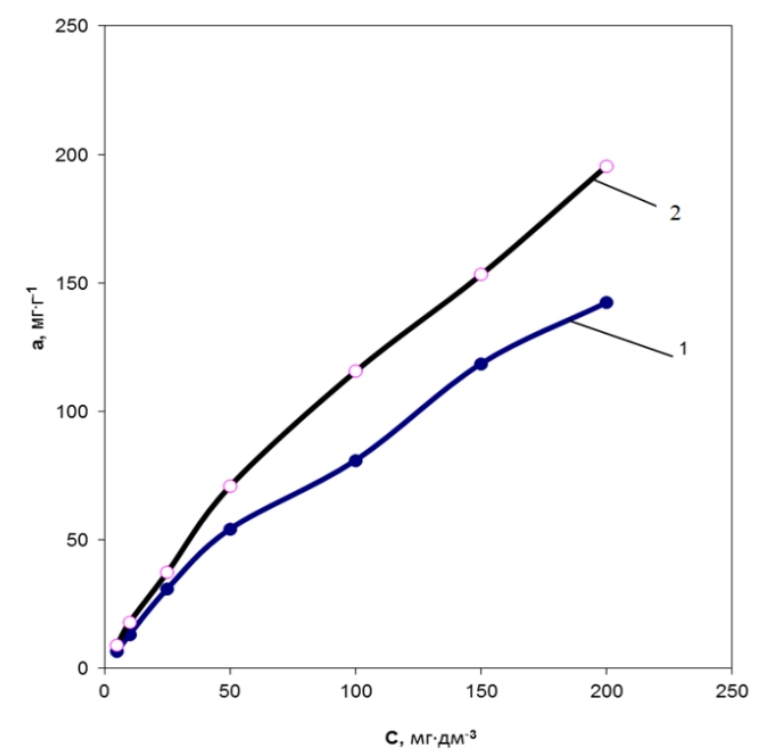

Рис. 1. Изотермы адсорбции стрептомицина: 1 - АУ-1; 2 - СКТ

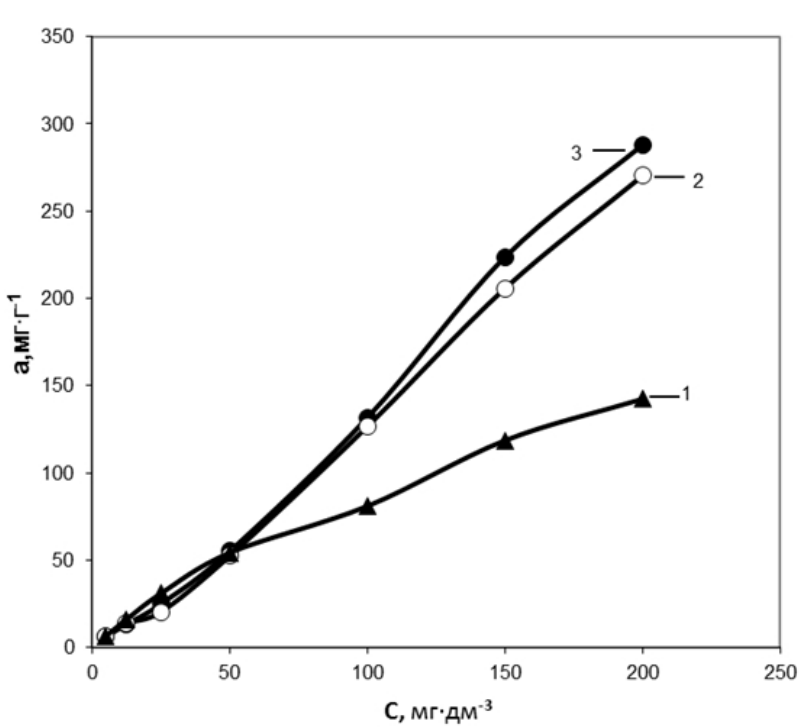

Рис. 2. Изотермы адсорбции на образцах АУ-1 при дозах окислителя $\left(\Gamma^{\cdot} \Gamma^{-1}\right): 1-0,0 ; 2-15,0 ; 3-30,0$ 
Отсутствие эффекта повышения величины адсорбции на окисленных образцах угля для начального участка изотерм обусловлено, видимо, более высоким содержанием кислотных групп (основных поставщиков ионов $\mathrm{H}^{+}$в раствор) на поверхности относительно концентрации стрептомицина и, как следствие, снижением рН раствора. Данные таблицы 2 подтверждают отмеченное.

Из полученных данных следует, что для повышения адсорбционной способности угля в области малых концентраций стрептомицина необходима добавка щелочного реагента с целью поддержания рН в нейтральной или слабощелочной среде.

Ранее $[14,15]$ было показано, что при расчете адсорбции паров и газов, а также растворенных 3В, с использованием уравнения теории объемного заполнения микропор, в области низких концентраций имеют место особенности, обусловливающие заметные расхождения экспериментальных и расчетных данных. В связи с поставленной в работе задачей представляло интерес выявить уравнение изотермы, позволяющее рассчитывать величину равновесной адсорбции стрептомицина из водных растворов в широком интервале возможных в практике концентраций с минимальной погрешностью.

Наиболее часто для расчета равновесной адсорбции ЗВ из растворов используется уравнение Ленгмюра. Возможность применения его подтверждается при соблюдении линейной зависимости в координа$\operatorname{Tax} \mathrm{C} / \mathrm{a}-\mathrm{C}$.

Из рисунка 3 видно, что линейная зависимость в отмеченных координатах уравнения Ленгмюра не соблюдается. Следовательно, можно допустить, что адсорбция стрептомицина происходит не по механизму мономолекулярного заполнения поверхности; во всяком случае он не является основным при адсорбции стрептомицина.

Изотерма адсорбции в координатах линейной формы уравнения БЭТ $\mathrm{C} /\left(\mathrm{a}\left(\mathrm{C}_{\mathrm{H}}-\mathrm{C}\right)\right)-\mathrm{C} / \mathrm{C}_{\mathrm{H}}$, (здесь $\mathrm{C}_{\mathrm{H}}-$ растворимость стрептомицина, мг·дм ${ }^{-3}$ ) по форме аналогична изотерме Ленгмюра, следовательно, полимолекулярная адсорбция в изученной области концентраций стрептомицина существенно не проявляется.

С учетом того, что активные угли классифицируются как микропористые адсорбенты, а также при допущении, что адсорбция стрептомицина может происходить не только в объеме крупных микропор, но и мелких переходных пор, нами была проверена возможность использования для расчета величины адсорбции уравнения Дубинина - Радушкевича (ДР):

$$
a=\frac{W}{v} \cdot \exp \left[-B \cdot\left(\frac{T}{\beta} \lg \frac{C s}{C}\right)^{2}\right]
$$

где $W$ - предельный объем адсорбционного пространства, $\mathrm{cm}^{3} \cdot \Gamma^{-1} ; v-$ мольный объем, $\mathrm{cm}^{3} \cdot \mathrm{моль}^{-1}$; $B$ - структурная константа, град ${ }^{-2} ; \beta$ - коэффициент подобия, безразмерный; $T$ - температура адсорбции, К; $\mathrm{C} s-$ растворимость адсорбтива, мг:дм ${ }^{-3}$.

Из рисунка 4 следует, что линейная зависимость в координатах $\operatorname{lga}-(\lg \mathrm{CH} / \mathrm{C})^{2}$ для обоих активных углей практически достигается; при значениях $2<\mathrm{n}<2$ такая зависимость не соблюдается, нарушаясь, как правило, начиная с концентрации 100 мг·дм ${ }^{-3}$ и ниже. На основе рисунка 4, исходя из отрезков, отсекаемых на оси ординат при продолжении прямых линий $(\lg (w / v))$ и тангенсов углов их наклона, получены значения констант, необходимых для практического применения уравнения ДР (табл. 3).

Таблица 2. Изменение $\mathrm{pH}$ водной вытяжки угля после адсорбции стрептомицина $($ Со $=50$ мг·дм-3

\begin{tabular}{c|c|c}
\hline Активный уголь & Доза $\mathrm{H}_{2} \mathrm{O}_{2}, \Gamma \cdot \Gamma^{-1}$ угля & рН раствора \\
\hline АУ-1 & 0 & 5,85 \\
Окисленные образцы АУ-1 & 7,5 & 5,36 \\
& 15,0 & 5,29 \\
& 30,0 & 5,13 \\
\hline
\end{tabular}

Таблица 3. Константы уравнения ДР

\begin{tabular}{c|c|c|c|c}
\hline Активный уголь & $\mathrm{W} / \mathrm{v}$, ммоль $\Gamma^{-1}$ & $\mathrm{~W}, \mathrm{~cm}^{3} \cdot \Gamma^{-1}$ & $\operatorname{tg} \alpha$ & $\mathrm{B}$, град \\
\hline СКТ & 1,08 & 0,59 & 0,160 & $26,4 \cdot 10^{-6}$ \\
$\mathrm{AУ-1}$ & 0,75 & 0,41 & 0,147 & $23,9 \cdot 10^{-6}$ \\
\hline
\end{tabular}




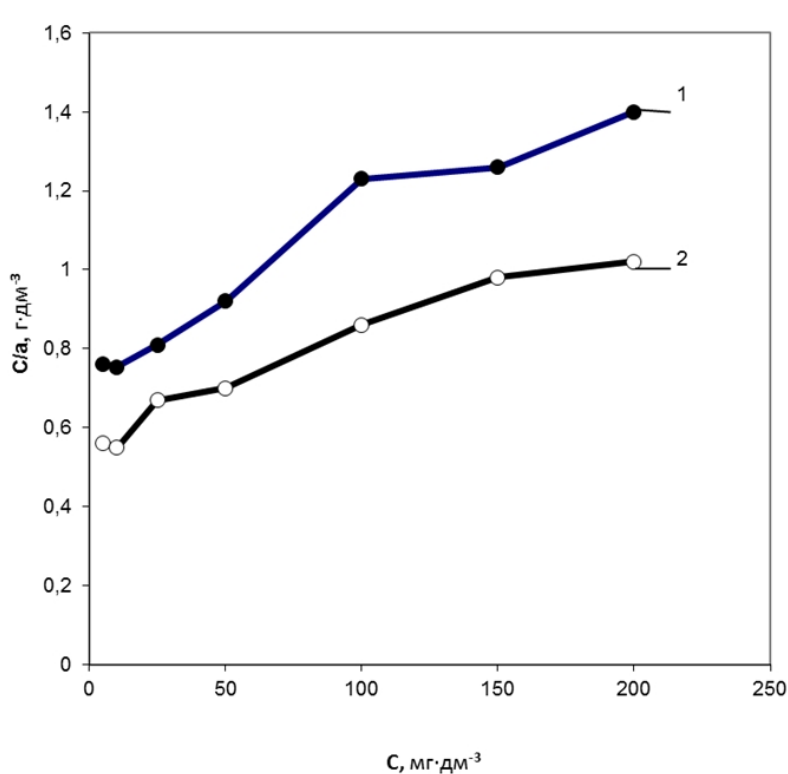

Рис.3. Изотермы адсорбции в координатах уравнения Ленгмюра: 1 - АУ-1; 2 - СКТ

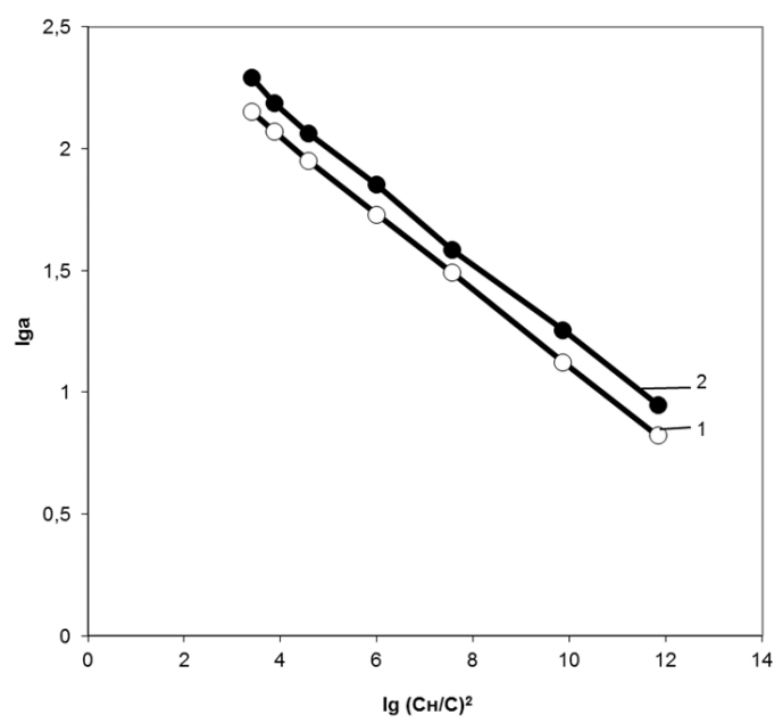

Рис. 4. Изотермы адсорбции в координатах уравнения ДР: 1 - АУ-1; 2 - СКТ

Значение мольного объема находили из известного значения предельного адсорбционного объема для угля СКТ $-\mathrm{W}=0,59 \mathrm{~cm}^{3} \cdot \Gamma^{-1}[6]$ и соотношения $\mathrm{W} / \mathrm{v}: \mathrm{v}=0,59 /\left(1,08 \cdot 10^{-3}\right)=546,3 \mathrm{~cm}^{3} \cdot$ моль $^{-1}$. Значение мольного объема стрептомицина, рассчитанное по способу Бенсона [16], составляет $531,4 \mathrm{~cm}^{3} \cdot$ моль $^{-1}$. Относительная погрешность расчета среднего значения мольного объема составляет 1,95\%. С учетом величины мольного объема было определено значение предельного адсорбционного объема для угля АУ-1 (табл. 3); по соотношению мольных объемов стрептомицина и бензола было найдено значение коэффициента подобия.

Среднее значение относительной погрешности расчетов по уравнению ДР в изученном интервале концентраций составляет: для угля АУ-1 - 6,60\%; для угля СКТ - 5,08\%.

Следует отметить, что линейная форма изотерм адсорбции стрептомицина на окисленных образцах АУ-1 во всех рассмотренных случаях не соблюдается; отклонения наблюдаются при концентрациях, меньших 100-50 мг·дм ${ }^{-3}$.

\section{Вblводbl}

Очистка водных растворов (сточных вод) от стрептомицина может быть осуществлена с применением активного угля (парогазовой активации) на основе корневища и корня элеутерококка; повышение адсорбционной активности угля достигается путем поддержания значения рН в нейтральной и слабо щелочной среде.

Применение окисленного активного угля представляется целесообразным при концентрациях стрептомицина в сточных водах более $100 \mathrm{мг \cdot дм}{ }^{-3}$.

Для расчета равновесной адсорбции стрептомицина при концентрациях его не более 200 мг·дм ${ }^{-3}$ в водном растворе рекомендуется использовать уравнение Дубинина - Радушкевича.

\section{Список литературы}

1. Li Shi-zhong, Li Xiao-yan, Wang Dian-Zuo. Membrane (RO-UF) filtration for antibiotic wastewater treatment and recovery of antibiotics // Separ. and Purif. Technol. 2004. Vol. 34, N1-3. Pp. 109-114.

2. Лопухин Ю.М., Кельцев Н.В., Рябов А.В. и др. Исследования в области адсорбционной очистки крови // Адсорбенты, их получение, свойства и применение. Л., 1978. С. 219-225.

3. Стрелко В.В., Галинская В.И., Давыдов В.И. и др. Сравнительное изучение некоторых углеродных гемосорбентов // Адсорбция и адсорбенты. Киев, 1976. Вып. 4. С. $29-37$.

4. Ходарченко Г.Б., Тихонов О.И., Грицан Л.Д. и др. Изучение адсорбции левомицетина энтеросорбентом кремнеземного происхождения силиксом // Вестник фармации. 2003. N4(36). C. 68-70.

5. Тимофеева А.В., Ильина М.В., Иванова В.Т. и др. Исследование процессов сорбции и десорбции антибиотиков разных групп на многослойных углеродных нанотрубках типа «Таунит» // Химия и химические технологии: материалы Междунар. научн. конф. Praha, 2013. Т. 65. С. 47-54. 
6. Rivera-Utrilla J., Prados-Joya G., Sánchez-Polo M., Ferro-García M.A., Bautista-Toledo I. Removal of nitroimidazole antibiotics from aqueous solution by adsorption/bioadsorption on activated carbon // Journal of Hazardous Materials. 2009. Vol. 170, N1. Pp. 298-305.

7. Вяхирев Д.А., Шишунова А.Ф. Руководство по газовой хроматографии. М., 1987. 335 с.

8. Boehm H.P. Chemical identification of surface groups // Advances in Catalysis. 1966. Vol. 16. Pp. 179-274.

9. Бутырин Г.М. Высокопористые углеродные материалы. М., 1976. 192 с.

10. Ануров С.А. Физико-химические аспекты адсорбции диоксида серы углеродными адсорбентами // Успехи химии. 1996. Т. 65 , вып. 8. С. 718-731.

11. Экспериментальные методы в адсорбции и молекулярной хроматографии / под ред. Ю.С. Никитина, Р.С. Петровой. М., 1990. 318 с.

12. Коваленко Л.И., Родионова Г.М. Руководство к лабораторным занятиям по фармацевтической экологии / под ред. А.П. Арзамасцева. М., 2007. 176 с.

13. Грег С., Синг К. Адсорбция. Удельная поверхность. Пористость. М., 1984. 306 с.

14. Григорьев Л.Н., Александрова Т.А. Особенности адсорбции паров и газов в области низких концентраций // Журнал прикладной химии. 2010. Т. 83, №2. С. 239-243.

15. Григорьев Л.Н. Александрова Т.А., Шанова О.А. Особенности адсорбции растворенных веществ в области низких концентраций // Журнал прикладной химии. 2011. Т. 84, №6. С. 922-926.

16. Столяров Е.А., Орлова Н.Г. Расчет физико-химических свойств жидкостей : справочник. Л., 1976. 112 с.

Поступило в редакцию 17 февраля 2015 г.

После переработки 4 ноября 2015 2. 
Grigoriev L.N..$^{I^{*}}$, Verencova L.G. ${ }^{l}$, Shanova O.A. ${ }^{2}$, Rodionova A.A. ${ }^{l}$ OBTAINING ACTIVATED CARBON FROM PLANT WASTE AND EVALUATION OF ITS ADSORPTION PROPERTIES

${ }^{\text {I}}$ St. Petersburg State Chemical-Pharmaceutical Academy, professora Popova st., 14, St. Petersburg, 197376 (Russia), e-mail: grig.lev@mail.ru

${ }^{2}$ St. Petersburg State Technological University of Plant Polymers, I. Chernykh st., 4, St. Petersburg, 198095 (Russia), e-mail: oshanova@gmail.com

On the basis of plant waste formed after extraction of the root and rhizome of Siberian ginseng, by gas activation was obtained samples of the activated carbon, for which defined pore volume and content of acidic and alkali groups. Shows the possibility of using the adsorption method for the extraction of antibiotics from aqueous solutions and wastewater for example, streptomycin. In comparative evaluation of equilibrium, adsorption of streptomycin from model wastewater shown that the obtained activated carbon at low concentration values practically does not differ much from industrial activated carbon with developed dimensional structure (such SKT-type) and can be recommended for practical applications in wastewater treatment.

It was found that at concentrations of streptomycin in water less than $100 \mathrm{mg} \cdot \mathrm{dm}^{-3}$ use the additionally oxidized activated carbon is not expedient as adsorbent.

To calculate the equilibrium adsorption of streptomycin on obtained activated carbon is proposed to use the equation Dubinin - Radushkevich with the experimentally determined constants; linear form of the equations of Langmuir and Brunauer, Emmett, Teller (BET) during adsorption at low concentrations of streptomycin on the obtained sample are not complied, which limits their use in the calculated practice.

It was determined that the higher values of the adsorption activity of the investigated sample activated carbon is achieved during process of adsorption treatment in a neutral to slightly alkaline solutions.

Keywords: activated carbon, oxidized activated carbon, adsorption, streptomycin, chemisorption, isotherms, equation isotherms, wastewater

\section{References}

1. Li Shi-zhong, Li Xiao-yan, Wang Dian-Zuo. Separ. and Purif. Technol., 2004, vol. 34, no. 1-3, pp. 109-114.

2. Lopukhin Iu.M., Kel'tsev N.V., Riabov A.V. and etc.. Adsorbenty, ikh poluchenie, svoistva i primenenie. [Adsorbents, their preparation, properties and applications]. Leningrad, 1978, pp. 219-225. (in Russ.).

3. Strelko V.V., Galinskaia V.I., Davydov V.I. and etc. Adsorbtsiia $i$ adsorbenty. [Adsorption and adsorbents]. Kiev, 1976, no. 4, pp. 29-37. (in Russ.).

4. Khodarchenko G.B., Tikhonov O.I., Gritsan L.D. and etc.Vestnik farmatsii, 2003, no. 4(36), pp. 68-70. (in Russ.).

5. Timofeeva A.V., Il'ina M.V., Ivanova V.T. and etc. Khimiia i khimicheskie tekhnologii: materialy mezhdunar. nauch. konf. [Chemistry and chemical technologies: Materials of international scientific conference]. Praha, 2013, vol. 65, pp. 47-54. (in Russ.).

6. Rivera-Utrilla J., Prados-Joya G., Sánchez-Polo M., Ferro-García M.A., Bautista-Toledo I. Journal of Hazardous Materials, 2009, vol. 170, no. 1, pp. 298-305.

7. Viakhirev D.A., Shishunova A.F. Rukovodstvo po gazovoi khromatografii. [Manual gas chromatography]. Moscow, 1987, 335 p. (in Russ.).

8. Boehm H.P. Advances in Catalysis, 1966, vol. 16, pp. 179-274.

9. Butyrin G.M. Vysokoporistye uglerodnye materialy. [Highly porous carbon materials]. Moscow, 1976, 192 p. (in Russ.).

10. Anurov S.A. Uspekhi khimii, 1996, vol. 65, no. 8, pp. 718-731. (in Russ.).

11. Eksperimental'nye metody $v$ adsorbtsii i molekuliarnoi khromatografii. [Experimental methods in molecular adsorption and chromatography]. Ed. Iu.S. Nikitin, R.S. Petrova. Moscow, 1990, 318 p. (in Russ.).

12. Kovalenko L.I., Rodionova G.M. Rukovodstvo k laboratornym zaniatiiam po farmatsevticheskoi ekologii. [Guide to laboratory work on the pharmaceutical environment]. Moscow, 2007, 176 p. (in Russ.).

13. Greg S., Sing K. Adsorbtsiia. Udel'naia poverkhnost'. Poristost'. [Adsorption. Specific surface area. Porosity]. Moscow, 1984, 306 p. (in Russ.).

14. Grigor'ev L.N., Aleksandrova T.A. Zhurnal prikladnoi khimii, 2010, vol. 83, no. 2, pp. 239-243. (in Russ.).

15. Grigor'ev L.N. Aleksandrova T.A., Shanova O.A. Zhurnal prikladnoi khimii, 2011, vol. 84, no. 6, pp. 922-926. (in Russ.).

16. Stoliarov E.A., Orlova N.G. Raschet fiziko-khimicheskikh svoistv zhidkostei : spravochnik. [Calculation of the physico-chemical properties of liquids. Directory]. Leningrad, 1976, 112 p. (in Russ.).

Received February 17, 2015

Revised November 4, 2015

\footnotetext{
* Corresponding author.
} 
